\title{
Management of Excess Weight and Obesity: A Global Perspective
}

\author{
Gundu HR Rao* \\ Laboratory Medicine and Pathology Director, University of Minnesota, USA
}

*Corresponding author: Gundu HR Rao, Laboratory Medicine and Pathology Director, Thrombosis Research, Lillehei Heart Institute, University of Minnesota, USA

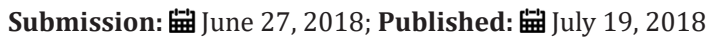

\begin{abstract}
Non-communicable diseases (NCDs), especially, hypertension, excess weight, obesity, metabolic syndrome, type-2 diabetes, and vascular diseases, have increased rapidly in the last two decades and have reached an epidemic status worldwide. Some experts have compared this increase in the incidence of these diseases as "tsunamis". Tsunamis' are seasonal and unpredictable whereas, these diseases are predictable and not seasonal. So, what are we going to do about this situation? Are we going to sit and wait for some miracle to happen? What are the member nations of the United Nations, World Health Organization, NCD Task Force going to do about this, besides writing and publishing scary reports of future economic and healthcare disasters? In this overview, we would like to discuss briefly the salient findings on this topic, initiate a healthy dialogue, request suggestions, positive comments, and offer few suggestions.
\end{abstract}

\section{Introduction}

An analysis based on Global Burden of diseases (2015) project sates, "that eight million largely preventable deaths from preventable diseases, costed 6 trillion dollars in lost economic welfare in lowand middle-income countries in 2015 (Harvard Gazette June 2018). Excess weight, obesity, and type- 2 diabetes, have reached epidemic proportions worldwide, and if not controlled in the near future, will cause a great economic havoc in the low-and middle-income countries. The American Heart Association (AHA) reports, that by $2030,40.5 \%$ of the adult US population will have some form of coronary artery disease (CAD). Between 2020 and 2030, real (208 billion) total direct medical cost of CAD management, are projected to triple from 273 billion to 818 billion. It is hard to believe, that excess weight and obesity have doubled in the last three decades. According to published reports, over 2.1 billion individuals are obese (30\%) worldwide, and all the related metabolic diseases, such as hypertension, metabolic syndrome, prediabetes, and vascular disease have reached epidemic status. The global burden of Disease (GBD) Obesity Collaborators analyzed the data from 68.5 million persons, to assess the trends in the prevalence of excess weight and obesity among children and adults between 1980-2015 in 195 countries [1-4]. According to their findings, in 2015, a total of 107 million children and 603 million adults were obese. Furthermore, they found that the prevalence of obesity had doubled in more than 70 countries. What is significant from these studies are, that they found the rate of increase in childhood obesity was greater than the rate of increase in the adult obesity. A trend that is very disturbing, and probably reflects the influence of change in lifestyle, lack of physical activity, consumption of fatty and energy dense foods. The authors of this very important study conclude, "That the rapid increase in the prevalence and disease burden of elevated body mass index (BMI) highlights the need for continued focus on surveillance of BMI, and identification, implementation and evaluation of evidence-based interventions to address this problem. In this overview, we will discuss few salient findings related to these issues and share our point of view, on this important topic related to excess weight, obesity, global predictions, warnings, and possible interventions.

A study done in Switzerland (2016) claims that, it is the largest population-based study, to assess the associations between the birth weight and adult levels of markers of glucose homeostasis, obesity, leptin and adiponectin in Europe [4]. Although this statement is true, in our opinion, ongoing studies at the CSI Holdsworth Memorial Hospital (HMH) in Mysore, India, are probably the oldest and largest on this topic [5,6]. Data on the infants born in this hospital has been kept from 1936 to present. The cohort called "Mysore Cohort" has been studied not only by the researchers at this hospital, but also by the epidemiology group of South Hampton, UK, under the leadership of Dr.Caroline Fall, Professor of international paediatric epidemiology, University of Southampton, UK. The seminal studies for over 70 years, has shown that children born in India, have high incidence (30-40\%) of low-birth-weight. These children with low birth weight, when they grow to adult hood, develop metabolic diseases at a greater rate, than normal weight children [5-9]. A study from the Harvard University, has 
demonstrated that daily supplement of micronutrients will to some extent alleviate this problem [10].

This problem is not unique to India; it really is a global problem, related to malnutrition of the pregnant women and the growing fetus[11-13]. China also faces similar problems, when it comes to the maternal and neonatal nutrition. In spite of the fact that we know of this risk for over 7 decades, no country has considered this condition as a serious public health burden. No country has established any interventions for reducing this known risk factor. Even in advanced countries like the USA, according to some experts, guidelines regarding the optimal pregnancy, nutrition and weight gain, management of low-birth and high-fetal-weight pregnancies, use of maternal glucocorticoids, and new born feeding strategies, have yet to be fully integrated [14]. We in Asia are adding millions of at "risk population", because of our indifference to develop better preventive healthcare policies. Now you can think about why no country has reversed or prevented the increase in the rise, or the prevalence of excess weight, obesity and type-2 diabetes. These are lifestyle diseases and hard to convince people to change their inherited or acquired habits. As the Harvard study has shown, these risks are preventable [10].

Swedish researchers studied over 62,000 Danish individuals and demonstrated that childhood overweight is associated with increased risk for developing type-2 diabetes in adulthood [15]. According to Kelly and associates, in children, oxidative stress and adipokine levels, worsen throughout the continuum of obesity. They conducted a study to assess the subclinical inflammation, fasting insulin and endothelial dysfunction, before and after exercise in overweight children. They found in these children, inflammatory marker C-reactive protein was an independent component, compared with fasting insulin. Just eight weeks of exercise improved cholesterol and endothelial dysfunction in these children, without significant weight loss [16]. A recent study by Buscot and associates, examined the question of whether or not, child-to adult body mass index (BMI) trajectories are associated with different levels of adult cardio metabolic risks [17]. The authors concluded that the long-term BMI trajectories that reach or persist at high levels were, indeed associated with increased CVD risk in adulthood.

Fincane and associates reported important findings related to alarming trends of increasing body-mass index (BMI) worldwide, and the effect of this excess weight on the growing incidence of cardiovascular disease and type-2 diabetes [18]. One of the surprise findings of this study was, that about $25-30 \%$ of obese people (Healthy Obesity?) might not be at increased risk of metabolic diseases. This brings up the question about, whether all forms of obesity are the same. If not how do they differ in the risk development and progression? According to them, decreased visceral fat mass, lower ectopic fat accumulation in the skeletal muscle and predominantly in the liver determined whether a benign or malign obesity was present $[18,19]$. A collaborative study between the staff at the Madras Diabetes Research Foundation (MDRF), Chennai, India, and the staff of Laboratory Medicine and Pathology, and Epidemiology Departments, University of Minnesota, concluded that "Compared to the US, waist-hip ratio is significantly higher in men and women from India" [20-22]. These results support the hypothesis that South Asians are particularly predisposed towards accumulation of visceral fat in the abdominal regions (central abdominal obesity). If we were to go by the standard measurement used to measure obesity, by monitoring BMI, then we will miss most of the Asian individuals, since their BMI is lower than the Caucasians. Having said that, we want to emphasize, that ethnic variations should be considered in such studies, to determine the degree of obesity, and look at it from the perspective, whether or not such observed obesity is healthy kind or harmful kind? Dr. Mohan's group at the Madras Research Foundation (MDRF), assessed performance of six simple obesity indices, to identify adults with CVD risks in South Asian population [23]. The authors conclude that, "In light of mounting evidence that waist-based measurements offer the best performance in classifying diabetes and hypertension-two leading causes of death and disability in South Asians-clinical statements and populationbased surveys of South Asians, would do well to include waist circumference in the battery of anthropometric measurements".

At the molecular level, studies from the Children's National Memorial Hospital (CNMH) Washington DC, demonstrated a role for adipocytes-derived "tweets" from exosomes (miRNAs), to the growing fetus, which can modulate expression of gene profiles [24]. They have shown that adipocytes that exist in large quantities in visceral fat, "tweet" signals that cause down regulation of proteins impacting two key signalling pathways: the TGF- $\beta$ and Wnt $/ \beta$ catenin, associated with controlling chronic inflammation and fibrotic diseases throughout the body. To understand the implication of this new finding in the fetal origin of adult diseases, we have facilitated a bilateral study between the researchers at CNMH and KEM Hospital, Pune, India. Another interesting study to be considered from the point of view of risk prediction is the findings of the Framing Heart Study group. These researchers have found that five branched chain and aromatic amino acids have highly significant association with future development of diabetes: isoleucine, leucine, valine tyrosine and phenylalanine [25]. For those of us interested in this topic, almost no week goes without a major headline about the epidemic of metabolic diseases, vascular diseases, and the increase in health care burden, due to the galloping rise in these diseases. In spite of the fact, that according to some reports excess weight and obesity has doubled from 1980-2010, and in the same time period type- 2 diabetes has increased fourfold, reactions from the Government's, public health officials, and policy makers so far, are wholly inadequate and by and large, rely on self-regulation by the food and beverage industry. Furthermore, they argue, that it is up to the individuals to make the right choices.

According to Prof. Steven Gortmaker [26], although obesity and diabetes epidemic has been escalating for four decades, sustained prevention efforts have barely begun. He says in his article that emerging science and quantitative models has provided key insights into the dynamics of this epidemic. He further states, that 
forecasts suggest that high rates of obesity will affect our future population health and economics. The article that I am referring was published seven years ago and as a person interested in this topic, I can assure the readers that not much has changed in these years, as far as the prevention strategies are concerned worldwide, at the population level. In a recent article (2018), Professor Michael Lean and associates conclude, "that funding for research and treatment will be more rationally planned, if conditions such as inflammation, oxidative stress, endothelial dysfunction, subclinical atherosclerosis, metabolic syndromes, type-2 diabetes, hypertension, arthritis, asthma to some extent even cancer and depression, can be reframed as complications of obesity. They further state that, "research to contribute to effective ways to prevent and reverse obesity is needed on truly global scale" [27].

According to Claire Wang and associates, if the US trends in the increase of obesity continue, the prevalence of obesity in US adults will increase from its present level of $32 \%$ (that is about the level worldwide) to about $50 \%$ by 2030 , with increase in the cost up to $\$ 66$ billion per year for treatment of obesity associated diseases [28]. If the UK trends in the increase of obesity for 1993-2008 continue, the prevalence of obesity will rise from $26 \%$ to $48 \%$ by 2030 and the costs will increase by 2 billion pounds. The United States will not be able to treat its way out of the obesity epidemic, with current clinical practice says, Professor Steve Gortmaker, director of Harvard prevention research centre and professor of practice health sociology, in an article in Health Affairs [29]. The authors further elaborate, that reversing the trend of obesity will require expanded investment in primary prevention, focusing on a combination of interventions with broad population reach, proven individual effectiveness, and low cost of implementation. If this is the status of care in the most advanced nation in the world, the USA think of the situations in other less developed countries with huge populations.

\section{The US Chronic Disease Prevention Action Plan includes;}

1. Creating community environments that promote and supply healthy food and beverage choices and physical activity

2. Prevent childhood obesity through early child-care and schools

3. Expand the role of health care and health service providers and insurers in obesity prevention

4. Expand the role of public private employers in obesity prevention (Prevention Agenda 2013-2018: Preventing Chronic Disease Action Plan).

The summary statement states: the causes of obesity in the US are complex, occurring at social, economic, environmental and individual levels. There is no single solution sufficient to turn the tide on this epidemic. Successful prevention efforts will require multiple strategies, such as national, State, local policies, and environmental changes that promote and support more healthful eating and active living, and that reach large numbers of children and adults. These strategies must be supported and implemented in multiple sectors, including government agencies, businesses, communities, schools, child care, health care and worksites, to make the easy choice also the healthy choice.

In summary, at the global level, there is a broad range of population-level actions that governments should take to prevent childhood obesity. According to WHO, a comprehensive childhood obesity prevention strategy should incorporate aspects of each of the key components. Strategic investment is required to implement effective and culturally appropriate population-based childhood obesity prevention programmes and initiatives, and to ensure that they include vulnerable groups, such as children with disabilities. It is essential that such interventions occur across the whole population, in a variety of settings, and through multiple strategies [30]. A comprehensive childhood obesity prevention strategy will incorporate aspects of each of the key components, such that the range of interventions includes:a mixture of "topdown" and community-based actions in plans and programmes;a mixture of policy instruments, including legislative and financial tools, to ensure availability and affordability of healthy foods and physical activity opportunities; the integration of policies for childhood obesity prevention into existing structures as a measure to ensure sustainability of action;interventions across a range of settings, including early childcare settings, schools, and community organizations; the establishment of cross-sectoral oral platforms and a multisectoral approach to childhood obesity prevention.

\section{Conclusion}

In this brief overview, we have discussed the fetal origin of adult diseases, as well as increase in the incidence of metabolic diseases, such as excess weight and obesity worldwide. Millions of children Worldwide are born with poor nutrition, as well as with low-birth weight, and this condition to a large extent is precipitated due to maternal and fetal malnutrition. According to a Harvard study, this acquired condition could be prevented by timely interventions with nutritional supplements [10]. We also have discussed the molecular origin of metabolic diseases, due to micro RNA-derived tweets or due to altered amino acid metabolism. Further research should continue to develop appropriate interventions at this level. We have discussed various indices of obesity and their impact on the development of metabolic syndrome, type-2 diabetes, and vascular diseases. Several Major clinical trials have demonstrated, that managing modifiable risk factors could, reduce or reverse the CVD risks $[31,32]$. We have discussed the various projections cautioning us, about the impending global epidemic of metabolic diseases, and the extraordinary cost of managing the burden of these diseases. Since these epidemics are rapidly increasing, we do not have the luxury to wait and develop appropriate interventions, or to conduct expensive clinical trials, to find out which strategy is better for reduction, reversal or prevention of these diseases. On the other hand, it is possible to develop simple, novel clinical studies to come up with a variety of complementary therapies, to reduce the effect of obesity-related metabolic risks. In a short overview, it is not easy 
to provide all the solutions for a complex problem like Obesity epidemic. What we have tried instead is, to initiate a dialogue on this problem of global public health importance, so that readers, experts, healthcare providers, policy makers, think "out of the box", and come up with novel ideas of interventions for the reduction, of obesity-related complications.

\section{References}

1. World Health Organization (2016) Global burden of diseases (NCDs). Report prepared by the institute of health metrics and evaluation (IHME). Global Burden of Disease Report, Global Burden of Disease, The Lancet, USA.

2. NCD Risk Factor Collaboration (NCD-Ris-C) (2017) Worldwide trends in body-mass index, underweight, overweight, and obesity from 19752016: a pooled analysis of 2416 population-based measurement studies in 128.9 million children, adolescent, and adults. Lancet 390(10113): 2627-2642.

3. NCD Risk Factor Collaboration (NCD-Ris-C): (2016) Worldwide trends in diabetes since 1980: a pooled analysis of 751 population-based studies with 4.4 million participants. Lancet 387(10027): 1513-1530.

4. Jornaywaz FR, Vollenweider P, Bochud M (2016) Low birth weight leads to obesity, diabetes and increased leptin levels in adults: the colaus study. Cardiovascular Diabetology 15:73.

5. Rao GHR, Bharathi M (2016) Mother and child: First step for prevention of cardio metabolic disease. J Cardiol (Photon Journal) Photon 109: 179186.

6. Krishna M, Kalyanaraman K, Veena SR, Krishanveni GV, Karat SC, et al. (2015) Cohort profiles: The 1934-66 Mysore birth records cohort in south India. Int J Epidemiol 44(6): 1833-1841.

7. Barker DJP, Eriksson JG, Forsen T, Osmond C (2002) Fetal origin of adult disease: strength of effects and biological basis. Int J Epidemiol 31(6): $1235-1239$.

8. Forsen T, Eriksson J, Tuomilehto J (2000) The fetal and childhood growth of persons who develop type-2 diabetes. Ann Intern Med 133 (3): 176 182.

9. Lau C, Desai M, Ross MG, Rogers JM (2011) Fetal programming of adult disease: implications for prenatal care. Obstet Gynecol 117(4): 978-985.

10. Kawai K, Spiegelman D, Shankar AH (2011) Maternal multiple micronutrient supplementation and pregnancy outcomes in developing countries: meta-analysis and meta-regression. Bull World Health Organ 89(6): 402-411.

11. Wu G, Bazer FW, Cudd TA, Meininger CJ, Spencer TE, et al. (2004) Maternal nutrition and fetal development. J Nutr 134(9): 2169-2172.

12. Barker DJP, Clark PM (1997) Fetal under nutrition and disease in later life. Rev Reprod 2(2): 105-112.

13. Vostka RJ, Hassoun PM, Harvey KB (1998) Dietary L-arginine prevents fetal growth restriction in rats. Am J Obstet Gynecol 178(2): 242-246.

14. Lau C, Desai M, Ross MG, Ross MG (2011) Fetal programming of adult disease: Implications for prenatal care. Obstet Gynecol 117(4): 978-985.

15. Bjerregaard LG, Jensen BW, Angquist L, Merete O, Thorkild I, et al. (2018) Change in overweight from childhood to early adulthood and risk for type-2 diabetes. New Engl J Med 378: 1302-1312.
16. Kelly A, Wetzateon RJ, Kaiser DR, Steinberger J, Bank AJ, et al. (2004) Inflammation, insulin resistance and endothelial dysfunction in overweight children and adolescents. J Pediatr 145(6): 731-736.

17. Buscot MJ, Thomson TJ, Juonala, Sabin MA, Burgner D, et al. (2018) Distinct child-to-adult body mass index trajectories are associated with different levels of adult cardiometabolic risk. Eur Heart J 39(24): 22632270 .

18. Finucane MM, Stevens GA, Cowan MJ, Danaei G, Lin JK, et al. (2011) National, regional, and global trends in body-mass index since 1980: systematic analysis of health examination surveys and epidemiological studies with 960 country-years and 9.1 million participants. Lancet 377(9765): 557-567.

19. Stefan N, Kantartzis K, Machann J, Schick F, Thamer C, et al. (2008) Identification and characterization of metabolically benign obesity in humans. Arch Intern Med 168(15): 1609-1616.

20. Bajaj H, Pereira M, Anjana M, Raj D, Noel T, et al. (2014) Comparison of relative waist circumference between Asian Indian and US adults. Journal of Obesity, p. 10.

21. WHO Expert Consultation (2004) Appropriate body-mass index for Asian populations and its implications for policy intervention strategies. Lancet 363(9403): 157-163.

22. Deurenberg P, Yap M, Sevens G, Deurenberg P (2000) The paradox of low body mass and high body fat percent among Chinese, Malays and Indians in Singapore. Int J Obes Relat Metab Disord 24(8): 1011-1017.

23. Patel SA, Deepa M, Shivashankar R, Ali MK, Kapoor D, et al. (2017) Comparison of multiple obesity indices for cardiovascular disease risk classification in south asian adults: the CARRS study. PLoS One 12(4): e0174251.

24. Ferrante SC, Nadler E, Pillai DK, Hubal MJ, Wang Z, et al. (2015) Adipocyte-derived exosomal miRNAs: A novel mechanisms for obesityrelated disease. Pediatr Res 77(3): 447-454.

25. Wang TJ, Larson MG, Vasan RS, Cheng S, Rhee EP, et al. (2011) Metabolite profiles and the risk of developing diabetes. Nat Med 17(4): 448-453.

26. Gortmaker SL, Swinburn BA, Levy D, Rob C, Patricia L, et al. (2011) Changing the future of obesity: science, policy, and action. Lancet 378(9793): 838-847.

27. Lean ME, Astrup A, Roberts SH (2018) Making progress on the global management of obesity and weight management. BMJ 361.

28. Wang YC, Pherson K, Marsh T, Gortmaker SL, Brown M (2011) Health and economic burden of the projected obesity trends in the USA and UK. Lancet 378(9793): 815-825.

29. Gortmaker SL, Wang C, Long MW, Giles CM, Ward ZJ, et al. (2015) Three interventions that reduce childhood obesity are projected to save more than they cost to implement. Health Aff 34(11): 1304-1311.

30.WHO (2012) Population-based approaches to childhood obesity prevention. WHO Press, Switzerland.

31. Yusuf S, Hawken S, Ounpuu S, Dans T, Avezum A, et al. (2004) Effect of potentially modifiable risk factors associated with myocardial infarction in 52 countries (the INTERHEART study): Case-control study. Lancet 364(9438): 937-952

32. Khera AV, Emdin CA, Drake I, Natarajan P, Bick AG, et al. (2016) Genetic risk, adherence to a healthy lifestyle and coronary artery disease. N Engl J Med 375(23): 2349-2358. 
Creative Commons Attribution 4.0 International License

For possible submissions Click Here

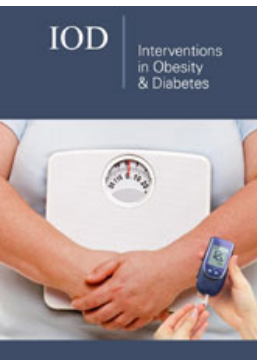

\section{Intervention in Obesity \& Diabetes}

\section{Benefits of Publishing with us}

- High-level peer review and editorial services

- Freely accessible online immediately upon publication

- Authors retain the copyright to their work

- Licensing it under a Creative Commons license

- Visibility through different online platforms 